\title{
Erratum to: International viewpoint and news: data and modelling platforms in environmental Earth sciences
}

\author{
Olaf Kolditz • Karsten Rink • Haibing Shao • \\ Thomas Kalbacher · Ralf Kunkel · Steffen Zacharias • \\ Peter Dietrich
}

Published online: 12 September 2012

(C) Springer-Verlag 2012

Erratum to: Environ Earth Sci (2012) 66:1279-1284

DOI 10.1007/s12665-012-1661-8

Unfortunately, the original article has been published incorrectly with errors in the title and author group. The complete and corrected title is given below:

"International viewpoint and news: data and modelling platforms in environmental Earth sciences"

One of the co-author Dr. Ralf Kunkel has not been included in the original publication.

The complete author list should read as follows:

"Olaf Kolditz, Karsten Rink, Haibing Shao, Thomas Kalbacher, Ralf Kunkel, Steffen Zacharias, Peter Dietrich".

The online version of the original article can be found under doi:10.1007/s12665-012-1661-8.

O. Kolditz · K. Rink · H. Shao - T. Kalbacher · S. Zacharias .

P. Dietrich

Helmholtz Centre for Environmental Research-UFZ,

Permoserstrasse 15, 04318 Leipzig, Germany

O. Kolditz ( $\square)$

Applied Environmental Systems Analysis,

Technische Universität Dresden, 01062 Dresden, Germany

e-mail: olaf.kolditz@ufz.de

R. Kunkel

Forschungszentrum Juelich GmbH, 52425 Juelich, Germany

P. Dietrich

Environmental and Engineering Geophysics,

Eberhard-Karls-University of Tübingen,

Hölderlinstraße 12, 72074 Tübingen, Germany 